\title{
Sobre la fórmula definicional acción y efecto de + verbo: Una nueva propuesta de tratamiento lexicográfico de los sustantivos de acción
}

\author{
JOSÉ-ÁLVARO PORTO DAPENA
}

Grupo Hispania, Universidade da Coruña

Un tipo de definición repetida hasta la saciedad en nuestros diccionarios y de no fácil comprensión para el usuario medio es aquella cuyo definiens consiste en un sintagma nominal constituido por la palabra acción - casi siempre acompañada, en coordinación copulativa o disyuntiva, por efecto- $\mathrm{y}$ un complemento formado por la preposición de seguida de un verbo en infinitivo, el cual representa normalmente el punto de partida de la derivación del sustantivo que actúa como definiendum. Entre los muchísimos ejemplos que podrían aducirse al respecto, valgan estos pocos tomados al azar del DRAE en su última edición:

1. alabanza. f. Acción de alabar o alabarse.

2. combinación. f. Acción y efecto de combinar o combinarse.

3. encomienda. $f$. Acción y efecto de encomendar.

4. encogimiento. $m$. Acción y efecto de encoger o encogerse.

5. liberación. f. Acción de poner en libertad.

6. parloteo. $\mathrm{m}$. Acción y efecto de parlotear.

7. propaganda. f. Acción o efecto de dar a conocer algo con el fin de atraer adeptos o compradores.

8. repartimiento. $\mathrm{m}$. Acción y efecto de repartir.

Esta fórmula definicional, introducida a lo que parece en nuestra lexicografía —quizás por influjo francés - por la propia RAE, en cuyo diccionario usual hace su aparición desde su primera edición, en 1780, bien que ya había sido ensayada en el Diccionario de autoridades, se generalizó en prácticamente toda la lexicografía española y ello pese a los problemas técnico-lexicográficos que plantea tanto desde un punto de vista práctico como teórico. En el orden práctico porque, aparte su monótona y machacona repetitividad, no resulta lógico poner a la par esta presunta acepción — por otro lado, bastante ambigua, pues puede incluir toda una serie de acepciones previstas en el correspondiente verbo - con otras, más o menos independientes de este, surgidas de la evolución semántica del sustantivo derivado verbal; pero a esto hay que añadir, entre otras cosas, que no infrecuentemente la coincidencia con las acepciones verbales es tan solo parcial y entonces no siempre los diccionarios señalan de un modo expreso las acepciones implicadas del correspondiente verbo. $\mathrm{Y}$ en el orden teórico ante todo porque, si bien es verdad que, formalmente, este modelo definicional parece coincidir con el de la típica definición 
aristotélica consistente en un sintagma endocéntrico, con un núcleo sintácticosemántico, que representa el género próximo, y un complemento preposicional correspondiente a la diferencia específica, la verdad es que, siguiendo el criterio, defendido por la generalidad de los lexicógrafos, según el cual en toda definición ha de existir equivalencia semántica - $\mathrm{y}$, por tanto, conmutabilidad - entre definiendum y definiens, dicho modelo habría que considerarlo inadecuado, dada la imposibilidad de llevar a cabo la conmutación, en cualquier contexto, del sustantivo definido por su correspondiente definiens.

Pues bien, a la consideración de esta doble problemática es a lo que voy a dedicar el presente artículo, que dividiré, lógicamente, en dos secciones o apartados generales: en el primero me ocuparé del aspecto teórico, en donde me propongo profundizar en la verdadera naturaleza de este tipo de definición -0 más bien pseudodefinición - , y en el segundo me referiré al aspecto práctico, analizando, por una parte, los problemas e inconvenientes más importantes que lleva consigo su adopción — cuestión por cierto ya ampliamente estudiada 1 - y, por otra, haciendo al final una propuesta de tratamiento lexicográfico de los sustantivos verbales con la que poder solucionar adecuadamente esa problemática.

\section{ASPECTO TEÓRICO}

No voy a entrar ahora, naturalmente, en la compleja cuestión de lo que en Lexicografía ha de considerarse o no definición, pues ello me daría pie por sí solo para un extenso artículo y, además, porque es algo ya tratado - espero que suficientementeen Porto Dapena (2014: 15 y ss.). Simplificando mucho, constituirá en principio definición lexicográfica toda expresión constituida por la entrada (definiendum) y un sintagma (definiens), cuando entre ambos se establece una relación de equivalencia, lo que significa que dicha expresión será susceptible de ser transformada en una oración atributiva de tipo ecuativo. $Y$ tal es el caso, efectivamente, de, por ejemplo,

9a. emigración. f. Acción y efecto de emigrar,

9b. emigración. f. Traslado de personas [a otro lugar de asiento] ${ }^{2}$,

dada la posibilidad

10a. emigración es la acción y efecto de emigrar,

10b. emigración es (el) traslado de personas [a otro lugar de asiento].

Y ello pese a que ambas definiciones responden, como veremos, a tipos muy distintos, sencillamente porque la equivalencia o ecuación se establece en niveles también diferentes: entre la palabra (nivel lingüístico) y lo que esta representa (nivel de la realidad) en el primer caso, y entre la palabra (nivel lingüístico) y su paráfrasis (nivel también lingüístico) en el segundo.

${ }^{1}$ Véase, por ejemplo, Ribera (1918), Lázaro Carreter (1971), García García-Serrano (2004) y Martín García (2011). Dejo de lado los aspectos morfológicos, ampliamente tratados, por no afectar directamente a la definición y tratamiento lexicográfico en general.

${ }^{2}$ Lo que va entre corchetes es, naturalmente, el contorno de la definición. 


\subsection{Esquema básico de los principales tipos de definición}

Son muchos los que piensan que una definición, para ser correcta - esto es, para ser una verdadera definición - ha de cumplir el segundo tipo de equivalencia, de modo que entre definiendum y definiens habrá de darse necesariamente una relación de sinonimia - manifestada en su conmutabilidad - y, yendo todavía más allá, el definiens ha de consistir en un verdadero análisis semántico o paráfrasis del definiendum. Por eso, de las dos definiciones de emigración antes vistas, tan solo 9b, frente a 9a, sería la propiamente correcta, por ser la única en que la conmutación es viable:

11a. En los años cincuenta hubo mucha emigración de España a América $\rightarrow *$ *En los años cincuenta hubo mucha acción y efecto de emigrar de España a América.

11b. En los años cincuenta hubo mucha emigración de España a América $\rightarrow$ En los años cincuenta hubo mucho traslado de personas de España a América.

Lo curioso, sin embargo, es que hasta ahora - al menos que yo sepa — nadie ha puesto en tela de juicio el carácter digamos «anómalo» del esquema definicional correspondiente a 9a, que, por el contrario, se viene asimilando de alguna manera al de 9b, del que se diferenciaría en todo caso por no presentar equivalencia sintáctica, aunque sí funcional $-\mathrm{o}$, mejor dicho, categorial- y léxica. Pero antes de entrar en esta y otras cuestiones, pienso que se hace necesario, para una mejor comprensión de lo que va a seguir a continuación, realizar un breve repaso de las posibilidades fundamentales de definición que se vienen adoptando tradicionalmente en los diccionarios ${ }^{3}$.

Ante todo lo primero que hay que determinar es la naturaleza del definiendum, es decir, qué es lo que realmente se pretende definir o — quizás mejor dicho-qué cosa representa el definiendum: una palabra o, por el contrario, la realidad a que esta se refiere en el uso corriente de la lengua. En este último caso, nos encontramos ante una definición ontológica, como la que encontramos en cualquier tratado científico o, simplemente, cuando, mostrándole un objeto a un interlocutor, le preguntamos qué es y él nos contesta con una caracterización más o menos aproximada de lo que ve. La definición propiamente lexicográfica o lingüística solo define palabras, porque las entradas o definienda de un diccionario están normalmente empleadas como representantes de sí mismas, esto es, metalingüísticamente; de ahí que, a su lado, aparezca siempre la indicación de su categoría y/o subcategoría, cosa que sobraría, como es natural, en una definición de tipo ontológico. Así pues, las definiciones de 12a y 12b,

12a. bit. Inform. Unidad de medida de cantidad de información,

12b. bit. $m$. Inform. Unidad de medida de cantidad de información,

pese a las apariencias, son completamente distintas, puesto que en el primer caso lo que se define es la realidad que llamamos bit, mientras que en el segundo se trata de definir el sustantivo masculino bit: la definición en el primer caso es ontológica y en el segundo lingüística o lexicográfica propiamente dicha.

Ahora bien, esta definición, que llamamos lingüística puede poner de manifiesto o bien el contenido de la palabra definida, y entonces tenemos una definición concep-

\footnotetext{
${ }^{3}$ Para un desarrollo más amplio de este punto, véase Porto Dapena (2014: 45 y ss.).
} 
tual, o bien otros aspectos de carácter funcional o pragmático, lo que da lugar a una definición funcional. Evidentemente, $12 \mathrm{~b}$ es una definición conceptual, puesto que de alguna manera conecta la palabra bit con un análisis del concepto (o, si se prefiere, prototipo) que esta representa, cosa que no ocurriría, por ejemplo, en

12c. bit. $m$. Inform. Acrónimo de binary digit,

que, obviamente, constituye una definición de tipo funcional.

Pero, respecto a las definiciones conceptuales, todavía hay que añadir que en unos casos - como en $12 \mathrm{~b}$ - lo expresado por el definiens es el concepto correspondiente a la realidad nombrada, es decir, lo que dice la definición es que la palabra bit sirve para indicar o designar la unidad de medida de la cantidad de información; la definición es, por tanto, conceptual designativa, mientras que, en este otro caso,

12d. bit. $m$. Inform. Elección entre dos posibilidades igualmente probables,

la definición sería conceptual de significado y al mismo tiempo parafrástica -es decir, el definiens está constituido por todo un sintagma o paráfrasis del definiendum - lo que en Lexicografía representa el tipo ideal por cuanto que es la única definición cuyo definiendum admite conmutación por el definiens:

\section{A un byte corresponde generalmente la cantidad de información de ocho bits $\rightarrow$ A un byte corresponde generalmente la cantidad de información de ocho elecciones entre dos posibilidades igualmente probables.}

\section{2. ¿Corresponde la fórmula acción de + verbo a una definición relacional?}

Ahora bien, habida cuenta de que las definiciones parafrásticas admiten a su vez, desde el punto de vista de la relación léxica existente entre el definiendum y el núcleo semántico o palabra que en el definiens expresa el contenido fundamental de la palabra definida, dos modalidades muy distintas, la sustancial y relacional, cabe preguntarnos, volviendo al tema central de este artículo, si la definición que responde a la fórmula acción (y/o efecto, hecho o acto) de + verbo en infinitivo no pertenecerá a la modalidad relacional, según yo mismo señalé en Porto Dapena (2006: 341, y 2009: 56), observación en la que coincido por cierto con Rafel (2005: 133).

El núcleo semántico en la fórmula definicional acción de + verbo no cabe duda de que está representado por el propio verbo, que en realidad aporta todo el contenido léxico del sustantivo verbal o definiendum. Es decir, volviendo al ejemplo 9a de emigración, lo que viene a decirnos la definición es que esta palabra no es léxicamente otra cosa que el verbo emigrar entendido como sustantivo, para lo que se requiere un elemento que trasponga ese verbo a la categoría de sustantivo, función que recaerá en el sustantivo acción, el cual actúa como núcleo sintáctico del definiens, aportando tan solo el contenido categorial de 'sustantivo'. De acuerdo con esto, pues, la definición en cuestión sería de tipo relacional y a su vez endocéntrico: el definiens es, efectivamente, desde el punto de vista sintáctico, un sintagma endocéntrico, cuyo núcleo es acción, y, semánticamente, la definición está montada en virtud de una relación semántica que no es de hiperonimia-hiponimia, como ocurre en las definiciones sustanciales, sino de 
desarrollo ${ }^{4}$. Pues bien, tales características las representaba yo, en 2006, bajo el siguiente gráfico:

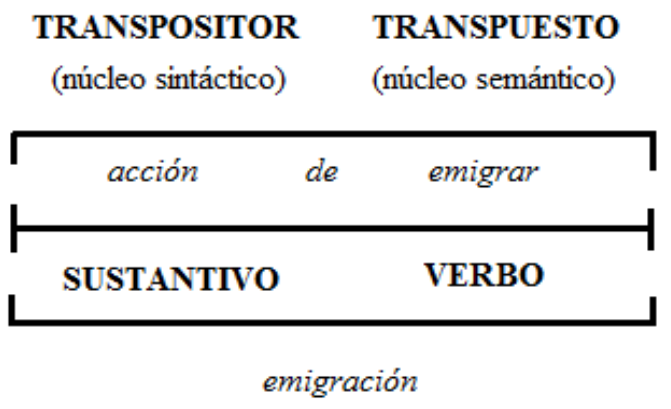

Semejante interpretación, sin embargo, no puede ser correcta sencillamente porque el modelo de definición que subyace a esta archirrepetida fórmula no cumple, según se ha demostrado en 11a, una condición esencial a toda definición conceptual de significado o parafrástica: la conmutabilidad del definiendum por el correspondiente definiens. Naturalmente, el caso de 11a no es esporádico ni excepcional, sino que, por el contrario, podemos erigirlo en norma general, como lo demuestran, entre otros muchísimos ejemplos, los siguientes, basados en las definiciones 1-8:

14. Se deshizo en alabanzas a su maestro $\rightarrow *$ Se deshizo en acciones de alabar a su maestro.

15. Se tomó una combinación de varios licores $\rightarrow *$ Se tomó un efecto de combinar varios licores.

16. Tengo que hacerte una encomienda $\rightarrow$ *Tengo que hacerte una acción de encomendar.

17. El contacto con el caracol produjo $s u$ encogimiento $\rightarrow * E l$ contacto con el caracol produjo su acción de encogerse.

18. Decretó la liberación de todos los presos $\rightarrow$ *Decretó la acción de poner en libertad a todos los presos.

19. Rosita y Cristina están siempre de parloteo $\rightarrow *$ Rosita y Cristina están siempre de acción de parlotear.

20. En la tele no hay más que propaganda $\rightarrow *$ En la tele no hay más que acción de dar a conocer algo con el fin de atraer adeptos o compradores.

21. Mañana haremos el repartimiento $\rightarrow$ *Mañana haremos la acción de repartir.

Los casos podrían, claro está, multiplicarse indefinidamente.

Lo chocante de semejante situación es que un sustantivo abstracto - $\mathrm{y}$, por lo tanto, de tan poca carga semántica-como acción (efecto o hecho) resulte inadecuado para sustituir a un definiendum de contenido más concreto y que, además, cabe clasificar efectivamente como sustantivo de acción. Este hecho, de todos modos, aunque no ha sido estudiado en profundidad, no constituye ninguna novedad, pues se produce asimismo en otras definiciones, como, por ejemplo, las correspondientes a medidas (así,

${ }^{4}$ Utilizo este término en el mismo sentido que Coseriu (1977: 179) por tratarse de una derivación en que se produce cambio de categoría. 
metro, vara, braza, ferrado, hectárea, etc.), a monedas, como euro, peso, peseta, dólar, a elementos químicos, etc.:

22a. metro. $m$. Medida de longitud equivalente a la diezmillonésima parte del cuadrante que pasa por París.

22b. El supermercado está a cien metros $\rightarrow{ }^{*}$ El supermercado está a cien medidas de longitud...

23a. ferrado. $m$. Medida de capacidad para áridos, usada en Galicia, que varía desde 13,13 hasta 16,151 .

23b. Tú mides el tiempo por ferrados $\rightarrow$ *Tú mides el tiempo por medidas de capacidad para áridos...

24a. euro. $m$. Unidad monetaria común a los estados de la Unión Económica y Monetaria europea.

24b. Gana 3.000 euros mensuales $\rightarrow$ *Gana 3.000 unidades monetarias comunes a los estados... mensuales.

Lo que ocurre en estos casos es que el sintagma definicional de tipo endocéntrico gira en torno a un sustantivo que, pese a su carácter clasificador, no forma propiamente parte del significado léxico del definiendum, del que, por tanto, no es - contra lo que a primera vista pudiera pensarse - un hiperónimo y ni siquiera un incluyente lógico. Se trata en todo caso de un indicador de una clase de realidad, que a nivel lingüístico, se correspondería más bien con un clasema o rasgo de subcategorización. Dicho de otra manera, palabras como metro, vara, euro, dólar o aluminio no son, respectivamente, hipónimos de medida, unidad monetaria y elemento químico; realmente no incluyen sus respectivos contenidos en su significado, lo que explica lo anómalo que resultarían frases del tipo

22c. *La palabra metro significa 'medida de longitud...'

23c. *El vocablo ferrado significa 'medida de capacidad para áridos, usada en Galicia...'

24c. *El sustantivo euro significa 'unidad monetaria común a...'

frente a estas otras, perfectamente aceptables:

22d. La palabra metro sirve para designar una medida de longitud...

23d. El vocablo ferrado designa una medida de capacidad para áridos, usada en Galicia...

24d. El sustantivo euro se usa como denominación de la unidad monetaria común a...

Lo que quiere decir que las definiciones aquí implicadas no son — contra lo que parecen pensar la Academia (2009): 405), García García-Serrano (2004: 83) y Martín García (2011: passim) — de significado o parafrásticas, sino referenciales: realmente lo clasificado como «medida» y «unidad monetaria» no es - repito- el significado del definiendum, sino la realidad designada por este.

Pues bien, como ya señalé en Porto Dapena (2014: 97, nota 13), el tipo de definición representada por la fórmula acción (y/o efecto, hecho o acto) de + verbo en infinitivo responde a esa misma caracterización: tampoco parece posible decir que

26a. "La palabra emigración significa 'acción de emigrar', sino más bien que

26b. La palabra emigración se usa para designar la acción de emigrar, 
entendido, naturalmente, emigrar no como representante de sí mismo - esto es, metalingüísticamente-, sino de la realidad o acción correspondiente ${ }^{5}$. La definición, pues, es claramente designativa: se limita a poner en relación el sustantivo verbal del definiendum con el tipo de realidad que representa; lo que no quiere decir que siempre que nos encontremos con un sintagma nominal encabezado por la palabra acción en el definiens, la correspondiente definición no pueda tener verdadero carácter parafrástico o de significado, cosa evidente en casos como los siguientes:

27. ataque. m. Acción ofensiva.

28. brutalidad. f. Acción torpe, grosera o cruel.

29. canallada. f. Acción o dicho propios de un canalla.

30. cursilada. f. Acción propia del cursi.

31. desafuero. m. Acción contraria a las buenas costumbres o a los consejos de la sana razón.

32. error. m. Acción desacertada o equivocada.

Donde, efectivamente, acción constituye un verdadero hiperónimo —o por lo menos incluyente lógico - de los correspondientes definienda, los cuales pueden ser conmutados por los respectivos definientes:

33. Interpretó su frase como un ataque al Rey $\rightarrow$ Interpretó su frase como una acción ofensiva al Rey.

34. Eso es una canallada $\rightarrow$ Eso es una acción propia de un canalla.

35. Pactar con ese partido es un error $\rightarrow$ Pactar con ese partido es una acción desacertada.

Nótese que, en estos casos, el sustantivo acción no tiene por objeto una subcategorización del definiendum, pues ni canallada, ni cursilada, desafuero y error son sustantivos subcategorizables como de acción, sino que la «significan» y, por tanto, acción juega aquí un papel de verdadero hiperónimo o incluyente lógico. Por otro lado, desde el punto de vista sintáctico, no se encuentra en aposición con ningún verbo, sino que forma parte de la estructura acción + adjetivo. Nos encontramos, pues, ante definiciones sustanciales, aunque algunas — así 29 y 30 - sean al mismo tiempo relacionales, puesto que el núcleo semántico no viene representado exclusivamente por la palabra acción, sino también por canalla y cursi.

\subsection{Análisis e interpretación de esta fórmula definicional}

Cabría, no obstante, preguntarnos si el vocablo acción posee en estos últimos casos el mismo significado - y, por tanto, es el mismo signo lingüístico- que el que aparece en las definiciones de los sustantivos deverbales. Acudir, desde luego, a los diccionarios convencionales para resolver tan importante cuestión, nos llevará seguramente a vernos metidos en un laberinto de difícil salida o envueltos y enredados en un círculo vicioso prácticamente insuperable. A mi modo de ver e independientemente de la función que la palabra acción tenga en uno y otro caso, a mí me parece fuera de duda que

${ }^{5}$ Así pues, el sintagma acción de emigrar es una aposición mediante un elemento genérico acción y otro específico emigrar unidos por la preposición de, y, por consiguiente, no cabe, por ejemplo, la paráfrasis «acción indicada por el verbo emigrar». 
se trata del mismo signo lingüístico ${ }^{6}$. Quizás el $D E A$ sea, en este aspecto, el diccionario más coherente, al caracterizar el vocablo, en su primera acepción — la más general—, funcionalmente, esto es, en segunda metalengua o metalengua de signo, a saber:

36. acción [...] Es el n abstracto que expresa la noción general de 'hacer'.

Es decir, se apunta a la noción de 'hacer' en su desenvolvimiento y a la vez potencialidad de producir un efecto o resultado. Y este es, no cabe duda, también el sentido que, a primera vista, le corresponde en la fórmula definicional de que venimos tratando, donde, por supuesto, el vocablo acción se toma en un sentido muy amplio y abstracto. Cabe matizar, no obstante, que en ejemplos como los comprendidos entre 27-32, acción se entiende más bien como 'hecho' — es decir, expresa la noción de 'hacer' vista como algo cumplido, temporalmente delimitado- o, quizás mejor, como 'efecto' o 'resultado'. Se trata, en todo caso, como se ve, de al menos dos sentidos que, por otro lado, se encuentran literalmente explícitos en la fórmula acción y efecto de + verbo, fórmula que por cierto la mayor parte de las veces, por no decir siempre, el usuario común del diccionario - $\mathrm{y}$ a veces incluso el propio lexicógrafo, que la utiliza de forma rutinaria o casi mecánica - no llega a discernir plenamente por su indudable va$\operatorname{guedad}^{7}$, planteándose así un problema suplementario en relación con la interpretación del definiens.

En este orden de cosas, mientras Ribera (1918: 292) relacionaba hace ya casi un siglo el sustantivo acción con el contenido activo, y el de efecto con el pasivo, en la actualidad Martín García (2011: 98) sostiene que la diferencia se encuentra en el sentido eventivo de acción frente al no eventivo de efecto. En mi opinión, sin embargo, pienso que no son dos, sino tres los sentidos comprendidos en la fórmula definicional, puesto que el sentido eventivo de que habla Martín García cabe desdoblarlo, atendiendo al aspecto o Aktionsart, según que este implique o no una delimitación temporal de la acción. Veamos:

a) En primer lugar, si partimos de un sustantivo verbal como, por ejemplo, falsificación, podemos interpretar ante todo que este puede expresar la acción o proceso mismo sin más, esto es, sin delimitación temporal alguna, como ocurre en el contexto

37. Han detenido una red de delincuentes que se dedicaban a la falsificación de ropa (= a falsificar ropa).

Notemos que el sustantivo en este caso es susceptible de construirse con un verbo que indica comienzo de la acción o la intención de llevarla a cabo tales como comenzar, empezar, intentar u otro equivalente ( $«$ Se proponían la falsificación de billetes de cincuenta euros»).

${ }^{6}$ El DUEAE señala tres acepciones distintas, de las cuales las dos primeras corresponderían a casos como los de 29-32, es decir, cuando la palabra acción se emplea sola o acompañada de un complemento que no sea verbo, y la tercera correspondería justamente a la fórmula definicional acción de + verbo.

${ }^{7}$ Precisamente, la elaboración del artículo, ya citado, de Ribera (1918) obedeció, como señala este en su introducción, a un encargo del entonces director de la Academia con el fin de aclarar el significado que en la fórmula definicional presentan los sustantivos acción y efecto. 
b) Se refiere, en cambio, al efecto o resultado de la acción, en

38. Aquel Picasso era en realidad una falsificación (= era un cuadro falsificado).

El sustantivo en cuestión admite generalmente el uso del plural ( $« E n$ relojería hay muchas falsificaciones») o llevan complementos temporales con preposición; su referencia a un efecto o resultado es especialmente clara cuando este tiene, como en el ejemplo propuesto, naturaleza material ${ }^{8}$.

c) Y, finalmente, indica el hecho - como algo consumado o producido en el tiempo- en este otro contexto:

39. Lo multaron por la falsificación de unos documentos (= por el hecho de haber falsificado unos documentos).

En este caso el sustantivo admite, por ejemplo, datación, duración o complementación temporal (sin preposición) e incluso la compañía de verbos como ocurrir, suceder, tener lugar u otros semejantes («La falsificación se realizó en $2010 »)$.

Esto quiere decir que los vocablos de significado más general, acción, efecto y, raras veces, hecho o también acto, que aparecen en la fórmula definicional aquí estudiada, vienen a conformar el siguiente paradigma léxico:

\begin{tabular}{|l|c|c|}
\cline { 2 - 3 } \multicolumn{1}{c|}{} & $\begin{array}{c}\text { SIN DELIMITACIÓN } \\
\text { TEMPORAL }\end{array}$ & $\begin{array}{c}\text { CON DELIMITACION } \\
\text { TEMPORAL }\end{array}$ \\
\hline CAUSA & acción & hecho \\
\hline RESULTADO & \multicolumn{2}{|c|}{ efecto } \\
\hline
\end{tabular}

Conviene, no obstante, observar que acción, en el uso corriente de la lengua - y también a veces en la práctica lexicográfica-, puede adquirir contextualmente los contenidos propios de efecto y, sobre todo, de hecho, según ya hemos podido constatar más arriba, lo que lo hace todavía más ambiguo y explica que muchos diccionarios —así, el DUEAE de $\mathrm{Vox}^{9}$ - reduzcan la fórmula a, simplemente, acción de + verbo en infiniti-

\footnotetext{
${ }^{8}$ No ocurre, naturalmente, lo mismo cuando es inmaterial, circunstancia en que el sentido de 'efecto' puede estar más o menos difuminado y hasta confundirse con el de acción como hecho o acontecimiento, que es lo que ocurre por cierto en la propuesta de Ribera, cuando este dice (1918: 292) que «la acción es un hecho de la historia del agente» y «el efecto, un hecho de la historia del paciente». Nótese, sin embargo, que, por ejemplo, Mi conversación con Teresa puede entenderse como un hecho («Ayer mantuve una larga conversación con Teresa»), pero también como un efecto o resultado («Me dejó preocupado mi conversación con Teresa»).

${ }^{9}$ Hay que decir que, en general, en este diccionario se procura huir de la repetición de la fórmula, procurando definir mediante hiperónimos y, por lo tanto, acudiendo a definiciones de significado de tipo sustancial; pero en muchos casos se sigue el modelo tradicional:
40. aseveración. Acción de aseverar.
41. congelación. Acción de congelar.
42. lapidación. Acción de lapidar.
43. prevención. Acción de prevenir. 
vo, entendida acción - insisto- en un sentido muy amplio, digamos el mismo que cuando, siguiendo la tradición gramatical, decimos que «verbo es una palabra que indica acción ${ }^{10}$. No cabe duda, sin embargo, de que en tal caso se está utilizando la palabra acción en un doble o triple sentido, pues tres son sus posibles referencias, a cada una de las cuales debería corresponder, lógicamente, una definición distinta. Conviene de todos modos tener muy presente que, como es lógico, no todos los sustantivos de acción admiten las tres interpretaciones: de acuerdo con la RAE (2010: 342), ello depende unas veces de las características léxicas del derivado - yo añadiría también las del verbo de que este deriva - y otras de los contextos sintácticos en que se usa.

Ahora bien, esto nos lleva a plantearnos la idoneidad, desde el punto de vista lexicográfico, de la fórmula tradicional académica al juntar en un mismo sintagma o definiens las palabras acción y efecto - ya sea, como es lo más frecuente, en coordinación copulativa, ya sea en coordinación disyuntiva-, que en realidad viene a ser la suma o mezcla de al menos dos definiciones que debieran aparecer formuladas independientemente ${ }^{11}$; o sea,

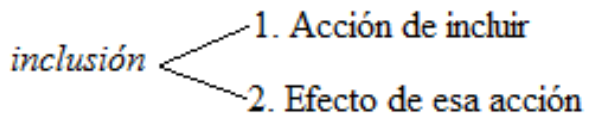

No voy a entrar ahora en la cuestión de si deben figurar como acepciones distintas o, más bien, 2 ha de ser tratada como subacepción de 1, del que puede entenderse como una variación, junto a un posible 3 , referido al hecho. Solo en el caso del $D E A$ se hace la separación, añadiendo a la definición formulada exclusivamente como acción de + verbo, la coletilla o extensión de $T b$ su efecto o Frec su efecto y expresiones por el estilo; así,

45. claveteo. Acción de clavetear. Tb su efecto.

Notemos por lo demás que el único sentido que, tanto en el DRAE como en el DUE, aparece de forma independiente es el encabezado por hecho o acto, de modo que, por ejemplo, en el primero de estos diccionarios, nos encontramos con casos como los siguientes:

${ }^{10}$ Lo que sin duda hace todavía más ambigua la definición. Por el contrario, sería más exacto hablar de acciones solo en el caso de sustantivos derivados de verbos que, siguiendo a Vendler, indican actividades, frente a los estativos o de estado, los de cumplimiento y los de logro, que darían lugar a sustantivos definidos como estados y hechos, respectivamente, y modificar en consecuencia la fórmula definicional en este punto. Por eso, podría resultar contradictorio definir, como hace el DUEAE — en consonancia con la tradición-, la palabra estancia como «acción de estar o permanecer cierto tiempo en un lugar». En este mismo sentido, Ribera (1918: 290 nota) cita el caso de pasión, definido en el DRAE como «acción de padecer», definición que continúa en la última edición. Digamos, en fin, que en la fórmula definicional, la palabra acción comprende también la noción de 'proceso' y hasta a veces de 'estado'. desnivelación:

${ }^{11}$ Así hace - siempre excepcionalmente - el DRAE en algunos casos; por ejemplo, en el de

44. desnivelación. 1. Acción de desnivelar o desnivelarse. || 2. Efecto de desnivelar o desnivelarse. 
46. asunción. 1. Acción y efecto de asumir. \|| 2. [...] Hecho de ser elevada al cielo la Virgen María en cuerpo y alma ${ }^{12}$.

47. radicación. 1. Acción y efecto de radicar. $\| 2$. Hecho de estar arraigado un uso, una práctica, una costumbre, etc.

48. encierro. Acción y efecto de encerrar o encerrarse [...] || 5. Acto de llevar los toros a encerrar en el toril,

donde, además, da la impresión de que se utiliza la fórmula hecho o acto de + verbo, cuando la palabra definida alude a la acción correspondiente a un caso concreto o específico. Por su parte el $D E A-\mathrm{y}$ en parte también el $D R A E$ - parece preferir el uso de hecho cuando se trata de sustantivos derivados de verbos de acontecimiento o acaecimiento, esto es, que indican un proceso que se verifica sin la intervención de un agente:

49. amanecer $^{2} m$ Hecho de amanecer.

50. caída $f 1$ Hecho de caer.

51. muerte I $f \mathbf{1}$ Hecho de morir.

52. cura $^{1} \mathbf{I} f \mathbf{1}$ Acción de curar [...]. b) Hecho de curarse;

si bien, en contradicción con este último caso, parece preferir exclusivamente acción, cuando el verbo se puede emplear como transitivo y solo indica acontecimiento en su uso pronominal o intransitivo, como es el caso de

53. entristecimiento $m$ Acción de entristecer(se). Tb su efecto.

54. estropeamiento $m$ Acción de estropear(se).

En otro orden de cosas, es conveniente señalar que la expresión acción y efecto de + verbo (y lo mismo ocurriría con acción, hecho y efecto de + verbo) resulta, al menos en principio, también bastante ambigua, pues, por un lado, podría entenderse en el sentido de que el sustantivo verbal definido designaría simultáneamente esas dos o tres posibilidades, lo que resulta lógicamente imposible, y, por otro, cabe entenderla — según acabamos de hacer, pues resulta lo más natural - como una alternativa en el sentido de que en unos casos representa la acción y en otros el efecto (o también el hecho). De ahí — pienso- que en algunos casos se utilice la conjunción disyuntiva en vez de la copulativa, como hace el $D R A E 2002$ en, por ejemplo,

55a. entrecomillado. Acción o efecto de entrecomillar ${ }^{13}$,

que a su vez podría interpretarse - también en teoría - como disyunción de equivalencia, en el sentido de que acción y efecto significarían exactamente lo mismo. En definitiva, la estructura sintáctica del definiens nos viene a corroborar que, como queda dicho, la fórmula definicional a que me estoy refiriendo no contiene una sola acepción, sino que es la suma de al menos dos, cada una de las cuales, lógicamente, debería dar lugar a una definición independiente.

Y termino este apartado señalando que no solo los usuarios, como ya sugerí más arriba, sino a veces los propios lexicógrafos, redactores de definiciones, no parecen tener, en la práctica, demasiado claro cuándo un sustantivo verbal representa una ac-

\footnotetext{
${ }^{12}$ Creo que la definición no es exacta, puesto que no se trata tanto del «hecho de ser elevada al cielo», sino más bien de 'ser asumida, absorbida o arrebatada por el cielo'.

${ }^{13}$ Nótese que en la edición del tricentenario la conjunción $o$ ha sido sustituida por $y$ : es decir, 55b. entrecomillado. Acción y efecto de entrecomillar.
} 
ción, un efecto o un hecho, pues de otro modo no se podrían explicar ciertas discrepancias que se detectan a veces en la formulación de las correspondientes definiciones, si comparamos unos diccionarios con otros. Así, comparando, por ejemplo, el DRAE con el $D E A$ nos encontraremos con que, entre otros muchísimos casos, mientras uno define tan solo como acción o como efecto, el otro lo hace al mismo tiempo como acción y efecto; por eso, para acorchamiento, el DRAE nos da la siguiente definición:

56a. acorchamiento. Efecto de acorcharse,

en tanto que en el $D E A$ esta misma palabra se caracteriza también como acción:

56b. acorchamiento. Acción de acorchar(se). Tb su efecto.

$\mathrm{Y}$, por el contrario, mientras en el $D E A$ los vocablos anuncio, aparcamiento, aplauso y culminación se definen únicamente como acciones:
57. anuncio. Acción de anunciar
58. aparcamiento. Acción de aparcar
59. aplauso. Acción de aplaudir
60. culminación. Acción de culminar,

en el $D R A E$ se hace como acciones y efectos. En términos generales, podemos decir que unas veces tiene razón la Academia - aunque probablemente tienda a pecar por exceso- y otras, en cambio, aciertan los autores del $D E A$, que, por otro lado, suelen errar más bien por defecto. A este último respecto, sorprenden bastante los casos de 47 y 49, ya que, evidentemente, tanto anuncio como aplauso pueden indicar también efectos, según puede observarse en contextos como estos:

61. En ese canal de TV no echan más que anuncios.

62. Al final de la función se escucharon muchos y reiterados aplausos.

Naturalmente, las discrepancias serán todavía mayores a medida que ampliamos el número de diccionarios comparados. Lo cierto es que a veces da la impresión de que la fórmula acción y efecto de funciona como un verdadero cliché que sin mayor reflexión adopta, por pura comodidad, el lexicógrafo para indicar simplemente que el definiendum es un sustantivo verbal o de acción.

\section{PUNTO DE VISTA PRÁCTICO}

Todo lo anterior nos lleva a plantear la existencia, en los artículos correspondientes a los sustantivos de acción, de dos tipos fundamentales de sentidos diferentes, que no convendría mezclar ni confundir: por una parte, los sentidos generales, establecidos bajo dos parámetros, según que, por un lado, apunten, como acabamos de ver, a la acción, al hecho y al efecto (que son los que podemos llamar más concretamente sentidos subcategoriales), y, por otro, los correspondientes al verbo de que deriva el definiendum (los sentidos verbales) y, en segundo lugar, los que, como producto de la evolución semántica, son exclusivos de dicho sustantivo (sentidos específicos). Partimos, pues, del siguiente esquema: 


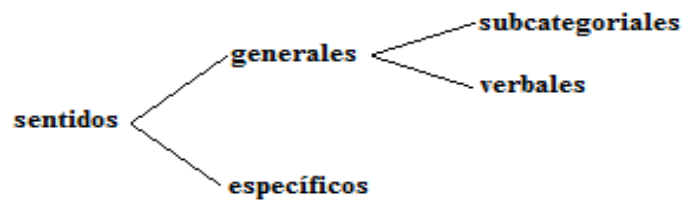

Así, por poner tan solo un ejemplo, considérese el artículo del $D R A E$ correspondiente a advertencia:

63. advertencia. f.1. Acción y efecto de advertir. || 2. Escrito, por lo común breve, con que en una obra o en una publicación cualquiera se advierte algo al lector. \|3. Escrito breve en que se advierte algo al público.

En 1 se resumen, según queda dicho, en un mismo enunciado los sentidos generales, representados únicamente por los subcategoriales, esto es, como acción y efecto (aunque falta como hecho o acto), mientras que en 2 y 3 se establecen los sentidos específicos. Nótese, por otro lado, que tal como está redactado 1 parece darse por sobreentendido que asume todos los contenidos de advertir (contenidos verbales), incluido el de 'fijar la atención, discernir u observar', bien es verdad que en este último caso se trata más de un hecho que de una acción ${ }^{14}$. En todo caso, como se ve, todas las posibilidades significativas o designativas se encuentran mezcladas $-\mathrm{o}$ sobreentendidas $-\mathrm{y}$ puestas a la par unas de otras, lo que, obviamente, va en detrimento de la claridad expositiva y, por tanto, de la capacidad informativa del diccionario.

\subsection{Problemas relacionados con los sentidos subcategoriales y verbales}

Lo normal, desde luego, es que sentidos subcategoriales y verbales aparezcan, como en el ejemplo anterior, implicados unos en otros; ambos constituyen, por tanto, los sentidos generales. Ello no supone ningún problema práctico cuando el verbo es monosémico $\mathrm{o}$, si es polisémico, el sustantivo verbal que se define puede utilizarse como indicador tanto de la acción como del efecto y hecho en todos y cada uno de los sentidos detectados en el verbo, como ocurre, por ejemplo, en 64 y 65 :

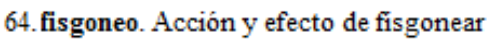

65.clarificación. Acción de clarificar.

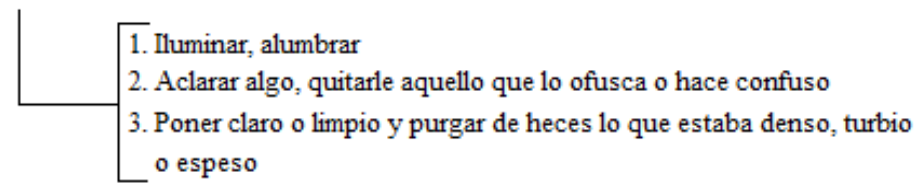

${ }^{14}$ De ahí que en el $D E A$ aparezca en acepción independiente y que, además, como acción se apunte solo a las acepciones 1 y 2 'avisar' y 'hacer saber' de advertir. 
El problema surge cuando o bien el sustantivo se corresponde tan solo con alguna o algunas acepciones del verbo o, por otro lado, no ofrece todas las posibilidades de sentidos subcategoriales previstos. Por eso, la definición de, por ejemplo,

66a. composición. Acción y efecto de componer

en el DRAE, al no corresponderse con acepciones de componer como

67. componer $[\ldots]$. 5. Ordenar, concertar o reparar,

no resulta adecuada. El $D E A$, como es sabido, soluciona muy satisfactoriamente este problema indicando entre corchetes los números o números y letras de los sentidos verbales involucrados; así,

66b. composición I $f \mathbf{1}$ Acción de componer [1,2,3 y 4].

Y, por su parte, el DRAE solo en algunas ocasiones ofrece definiciones independientes, esto es, como acepciones distintas, utilizando unas veces la misma fórmula definicional y otras, en cambio no; usa la misma fórmula, por ejemplo, en

68. fichaje. m. 1. Acción y efecto de fichar a un jugador, atleta o técnico deportivo. || 2. Acción y efecto de obtener los servicios o la ayuda de alguien,

en correspondencia con la acepción 3 de fichar, acepción que en realidad incluye dos sentidos diferentes:

69. fichar [...]. 3. Contratar a un deportista en un equipo o club, y, por ext., a una persona, generalmente de prestigio, para una determinada actividad.

Pero no ocurre lo mismo en este otro artículo:

70. ordenación [...]. 2. Acción y efecto de ordenar u ordenarse [...]. || 3. Colocación de la cosas en el lugar que les corresponde [...]. || 6. Mandato, orden, precepto.

donde las acepciones 3 y 6 se corresponden con 1 y 3 de ordenar, que dicen así:

71. ordenar [...]. 1. Colocar algo o a alguien de acuerdo con un plan o de modo conveniente [...]. 3. Mandar, imponer, dar orden de algo.

Desde luego, este última forma de proceder no parece tener mucho sentido, como no lo tiene - a mi juicio - intentar, según hacen otros diccionarios, evitar al máximo el uso de la fórmula utilizando en su lugar una definición conceptual de significado y a poder ser hiperonímica, adoptando como incluyente lógico uno o más sustantivos — generalmente también deverbales - de contenido más amplio, como ocurre en este caso, que tomamos del DUEAE:

72. desolación. Ruina y destrucción completa de un edificio, un territorio, etc., de manera que no quede nada en pie,

que en realidad representa la «acción y efecto» de desolar en su primera acepción:

73. desolar. Arruinar y destruir por completo un territorio, una superficie, un edificio, etc., de manera que no quede nada en pie,

lo que, además, llevará probablemente al usuario a tener que consultar el o los artículos correspondientes a arruinar y destruir. El procedimiento tampoco es ajeno al DRAE, donde encontrarnos asimismo algunos artículos de sustantivos verbales en que no se usa la consabida fórmula; pensemos, entre otros, en el caso de ofuscamiento: 
74. ofuscamiento. 1. Turbación que padece la vista por un reflejo grande de luz que da en los ojos, o por vapores o fluxiones que dificultan la visión. \| 2. Oscuridad de la razón, que confunde la ideas,

cuyas acepciones se corresponden con la 1 y 3 de ofuscar:

75. ofuscar. 1. Deslumbar, turbar la vista. || 3. Trastornar, conturbar o confundir las ideas, alucinar.

$\mathrm{Y}$ digo que este procedimiento no tiene mucho sentido no porque me parezca mal tratar de evitar la fórmula de acción y efecto de + verbo, que ciertamente resulta —insisto una vez más- demasiado repetitiva y a la vez ambigua por aglutinar de hecho con frecuencia múltiples sentidos tanto verbales como subcategoriales. Lo digo sencillamente porque, de ese modo, los sentidos específicos no aparecerán claramente diferenciados de los generales, cosa que me parece fundamental, pues son los específicos prácticamente la única justificación de que este tipo de sustantivos de acción den lugar, como observaré más adelante, a artículos independientes de los del verbo de que derivan o se relacionan semánticamente.

\subsection{Los sentidos especificos y su problema de confusión con los verbales}

Bien está, efectivamente, que tanto los sentidos subcategoriales, indicados fundamentalmente en la fórmula definicional por las palabras acción, efecto, hecho o acto, como los verbales tengan que presentarse en el diccionario - según acabamos de verde forma simultánea, pues ambos tipos tienen que ir en la práctica necesariamente unidos; pero en el caso de los sentidos específicos no ocurre lo mismo, lo que explica que no sean definibles mediante la consabida fórmula, que es lo que ocurre, como puede verse fácilmente, con 2 y 3 del ejemplo 63. Dado, sin embargo, que - según queda observado - a veces los diccionarios prescinden de la fórmula también en la definición de sentidos generales, se produce con facilidad la confusión entre los verbales y los específicos. Tanto es así que no infrecuentemente, junto a una definición explicitada mediante la fórmula a que me vengo refiriendo, los diccionarios - especialmente el de la Academia- repiten el mismo contenido mediante otro tipo de definición, como si de un sentido específico del definiendum se tratase; es el caso, pienso, de

76. operación. 1. Acción y efecto de operar. \| 2. Ejecución de algo,

donde 2 repite en otras palabras el sentido - o sentidos- expresados en 1. Lo mismo ocurre en

77. definición. 1. Acción y efecto de definir. \| 2. Proposición que expone con claridad y exactitud los caracteres genéricos y diferenciales de algo material o inmaterial,

pues, aunque 2 coincide tan solo parcialmente con 1, pone de manifiesto lo que podemos llamar «el efecto o resultado de definir», verbo que, según la primera acepción del propio $D R A E$, significa «fijar con claridad, exactitud y precisión el significado de una palabra o la naturaleza de una persona o cosa».

Ciertamente el parentesco semántico existente entre los sentidos que pueden considerarse específicos y los que se encuentran ya en el verbo es en la mayor parte de los casos evidente, lo que dificulta sin duda una separación nítida sobre todo a la hora de 
fijar las diversas acepciones. No hay que olvidar — claro está- que los sentidos específicos son siempre de alguna manera fruto de la modificación de los generales presentes ya en el verbo, sea por deslizamiento semántico (metáfora, metonimia, sinécdoque...), sea por especialización o extensión, etc. Por considerar tan solo un ejemplo de esto, pensemos en

78a. aviso. 1. Acción y efecto de avisar [...]. || 5. Embarcación de guerra pequeña y muy ligera, utilizada antiguamente para llevar pliegos y órdenes y, después, para otros usos auxiliares. \| 6. Tarom. Advertencia que hace la presidencia de la corrida de toros al espada cuando este prolonga el tercio de matar más tiempo del prescrito por el reglamento. || 7. Am. anuncio (|| soporte en que se transmite un mensaje publicitario).

Donde 6 corresponde sin duda a una especialización semántica del efecto de avisar en el sentido de 'advertir o aconsejar'; por su parte 7 implica una metonimia de continente por contenido, es decir, el sentido de aviso como 'efecto de avisar' pasa a indicar el soporte $\mathrm{u}$ objeto que contiene dicho aviso, $\mathrm{y}$, finalmente, en 5 se produce una nueva metonimia por el hecho de que el barco se usaba inicialmente como transporte de avisos, extendiéndose después - ya sin conexión aparente con el significado inicial de aviso - a cualquier tipo de barco auxiliar.

Normalmente, este parentesco semántico no supone especiales dificultades para la claridad del artículo lexicográfico, puesto que a cada sentido detectado corresponde una acepción diferente. El problema surge, sin embargo, en algunos diccionarios -así el de M. Moliner o el $D E A$-, donde se distingue entre acepciones y subacepciones, circunstancia en que no infrecuentemente un sentido específico es considerado como una subacepción de un sentido general introducido por la fórmula acción y efecto de + verbo. Es lo que ocurre, sin ir más lejos, con la acep. 6 de 78a, que en el $D E A$ de Seco y otros aparece registrada de esta otra forma:

78b. aviso [...] 1 Acción de avisar. Tb su efecto. b) Escrito en que se avisa algo. c) Señal o indicio [de algo futuro]. d) (Taur) Advertencia que el presidente hace al torero o al rejonedor cuando prolongan la faena más tiempo del reglamentario.

Lo que crea un problema evidente, pues no se especifica a cuál de los sentidos implicados en 1 se subordinan b, c y d: por una parte, ¿a aviso entendido como 'acción' o como 'efecto'? Y, por otro lado, ¿a cuál de los contenidos heredados de avisar? Para llevar a cabo esta estructuración del artículo de un modo claro, no habría otro remedio que separar - y definir independientemente - todos y cada uno de los sentidos generales que aquí aparecen indicados globalmente en $1 \mathrm{y}$, naturalmente, subordinar b, c y d al que correspondiese. Y no entro, naturalmente, en la cuestión — bastante peliaguda por cierto - de si la consideración de estos últimos sentidos, introducidos con letras minúsculas, están correctamente interpretados como subacepciones de 1: desde luego, para empezar, Moliner no coincide exactamente con esta decisión, como podemos ver en

78c. aviso. $1 \mathrm{~m}$. Acción de avisar. • Cosa que se avisa. • Escrito o palabras con que se avisa: 'Han pegado en la pared un aviso de la alcaldía'. || 2 (Para, Servir de) Castigo o escarmiento que sirve para que alguien no repita cierta cosa que, de repetirse, sería todavía de peores consecuencias. || 3 Barco de 
guerra muy pequeño y rápido, utilizado para llevar órdenes. $\| \mathbf{4}$ Taurom. Advertencia que hace el presidente de la corrida al torero cuando éste prolonga la faena de matar más tiempo del reglamentado. $\| 5$ Hispam. Anuncio.

Donde el sentido correspondiente a la Tauromaquia es una acepción independiente, y, por otro lado, solo cuando aviso se entiende como 'escrito' hay, efectivamente, coincidencia con Seco en la consideración como subacepción de 1.

\subsection{Propuesta para la solución de los problemas apuntados}

Visto todo lo anterior, pienso que la problemática planteada por el desarrollo de los artículos correspondientes a los sustantivos verbales de acción a que me estoy refiriendo podría resolverse muy favorablemente adoptando un procedimiento que en realidad ya se ha venido aplicando con éxito en la redacción del Diccionario "Coruña» de la lengua española actual (véase Porto Dapena y otros 2007: 35-39). Dicho procedimiento, básicamente, no consiste en otra cosa que en tratar esos sustantivos dentro de la microestructura de los verbos correspondientes en lo que a los sentidos generales se refiere, dejando los sentidos específicos para su tratamiento en artículos independientes, en los cuales esos mismos sustantivos figuren como entradas y a la vez se conecten, como es natural, mediante la correspondiente remisión, con los respectivos verbos. Aparte las ventajas prácticas que, como vamos a vez, este tratamiento lleva consigo, la separación se justifica además plenamente desde el punto de vista teórico, pues el paradigma o paradigmas de que estos sustantivos forman parte en sus sentidos generales son -en principio - muy distintos a los que corresponden en sus sentidos específicos: en el primer caso, efectivamente, hay que hablar, siguiendo a Coseriu (1977: 169), de estructuras secundarias, dado que los sustantivos en cuestión son en realidad desarrollos - esto es, derivados que implican cambio de categoría léxico-gramatical- de los correspondientes verbos, con los que, por tanto, forman paradigma léxico, mientras que en el segundo caso puede tratarse de estructuras primarias ya pertenezcan a clases léxicas o a campos semánticos, entre otros.

El hecho de formar parte del mismo paradigma léxico que los verbos de que derivan es sin duda la causa de la regularidad y paralelismo semántico que estos sustantivos presentan. Regularidad en cuanto a la definición empleada, expresada normalmente bajo la consabida fórmula - casi sacramental, que diría Ribera - de acción y efecto de + verbo, repetida hasta la saciedad y que, al fin y a la postre, aporta muy poca información acerca del definiendum, y paralelismo dada la coincidencia - total o parcialde los contenidos léxicos del sustantivo con los del verbo correspondiente. Y precisamente dicha regularidad nos ahorrará tener que repetir continuamente la tan poco eficaz fórmula si, dentro del artículo del verbo, incluimos el o los sustantivos deverbales marcándolos simplemente con la indicación categorial (sustantivo masculino o femenino) y subcategorial de acción, efecto, hecho o acto, y, además, para evitar toda posible ambigüedad, dicho registro lo hacemos dentro de la acepción o subacepción verbal correspondiente, con lo cual el sustantivo aparecerá a su vez — sin necesidad de una nueva definición - con el sentido verbal preciso.

Pero, obviamente, pese a la regularidad semántica —e incluso morfológica-que estos sustantivos presentan en relación con el verbo de que derivan (o al menos ofre- 
cen, en caso de no ser propiamente derivados, una relación semántica con dicho verbo idéntica a la de un verdadero derivado), no cabe duda de que no estamos hablando de formas de flexión verbal, lo que quiere decir que tales sustantivos constituyen realmente palabras independientes y que, por lo tanto, habrán de formar parte - lo mismo que los verbos - de la macroestructura del diccionario. Quiero decir con esto que, pese a ser estudiados, en sus sentidos generales, dentro de los artículos de los correspondientes verbos, también a su vez habrán de registrarse como lemas de artículos independientes, que consistirán en meras remisiones al verbo, cuando el sustantivo deverbal no posee ningún sentido específico, o en una remisión seguida de los sentidos específicos distribuidos en las correspondientes acepciones y subacepciones.

Como ejemplo de este procedimiento, me permito reproducir aquí dos artículos inéditos del Diccionario «Coruña», los correspondientes a iluminación e iluminar, tal como se encuentran redactados en este momento:

\section{8. iluminación. $f$. V. iluminar.}

1. Conjunto de luces u objetos para iluminar:

Ubicado en Lago Moreno. Servicios: sanitarios, duchas, agua caliente, proveeduría, luz individual, estacionamiento, iluminación (Weekend, 04/2003).

Las imágenes muestran algunas ejemplos del trabajo de diseño industrial y gráfico, a través de su línea de muebles, iluminación y lámparas, objetos para la decoración y línea gráfica vista a través de logotipos e isotipos (Trama. Revista de Arquitectura y Diseño, $\left.\mathrm{n}^{\mathrm{o}} 72,03 / 11 / 2000\right)$.

2. Inspiración, conocimiento intuitivo de las cosas:

Precisamente, la experiencia existencial y vivencial que sufría Colson como angustia durante su estada en París, se reveló poderosamente en su nuevo lenguaje; de ahí que haya manifestado ese misterioso llamado que, resonando en su conciencia desde hacía años, lo invitaba a establecer un contacto directo y sagrado con las expresiones de identidad que definen su origen mulato-negro; geografía en la que finalmente sembró la llama de su iluminación creadora y los despojos de su cuerpo como una entidad dramática y sujeto de la historia del sufrimiento, el estoicismo y la dignidad personal de un creador honrado y vivo aun (Revista Artes en Santo Domingo, año 2, no 7, 04-07/2003).

79. iluminar. v. 1. tr. [ alguien (suj.) una persona, animal o cosa (od.) <con algo lumino$s o>(\mathrm{cp})$.$] . Alumbrar o bañar de luz:$

a) En sentido material:

Según la policía, Stephanie llegó con su Jaguar y lo iluminó con sus focos delanteros, mientras él aflojaba los tornillos (Clarín, 19/01/1997).

- Actuando como suj. la luz o el objeto que la produce:

Si lo importante se refiere más al panorama que a las individualidades, por brillantes que sean, no cabe duda de que la pasarela de San Sebastián está obteniendo una nota muy alta en esta $45^{\mathrm{a}}$ edición. Los focos sólo se han encendido a tope para recibir a Jeremy Irons y a Willem Dafoe y volverán a iluminar a Michael Douglas durante el fin de semana (El País, 24/09/1997).

En el primer otoño de mi memoria subí a un navío que había encallado en unos bajíos. La luz del faro Villano sólo había podido iluminar la niebla (El Mundo, 21/09/1996).

- El objeto que emite la luz puede actuar también como obj. directo: 
Feliz casualidad cratiliana que al botón de iluminar la pequeña pantalla se le llame interruptor (El País, 04/09/1977).

En sentido figurado:

Bajo el signo y los estigmas del poder del oro, de la acumulación del dinero, del poder político y religioso, cuya degradación extrema fue el combustible que iluminó las lámparas del Renacimiento (Roa Bastos, Vigilia del Almirante, 207).

- En construcción absoluta:

Para consumir menos energía a la hora de iluminar es recomendable utilizar lámparas fluorescentes compactas en todos los casos posibles (El Nacional, 02/10/2000).

- prnl. Pasando a suj. el obj. directo o persona, animal o cosa que recibe la luz, 'llenarse de esta':

El horizonte se iluminó como acostumbraba a hacerlo en un día de verano (La Vanguardia, 16/07/1995).

- prnl. El suj. puede ser también el objeto que emite o produce la luz, equivaliendo entonces a 'lucir, emitir luz':

El juego está pensado para que una persona de movilidad reducida juegue con su familia o amigos. Posee un dado electrónico que se activa con un pulsador de mano o de soplo. Cuando la persona minusválida mueve su ficha se ilumina una luz en la casilla correspondiente. El dispositivo ha sido realizado con ayuda de la Universidad Carlos III (Accesible. Revista de información sobre discapacidad, $\mathrm{n}^{\circ}$ 10, 03/2000).

Cuando la salida equivale a 1 la bombilla se ilumina, cuando vale 0 la bombilla se queda apagada (D. Rdgz. Calafat, Informática avanzada al alcance de todos).

En este sentido, puede encontrarse incluso usado como intransitivo:

Son unos operadores electrónicos que consiguen convertir toda la corriente eléctrica en luz, sin perder, como en las bombillas incandescentes, una parte en forma de calor. En contrapartida, los LED aportan menos luz, de forma que sólo se les puede utilizar para señalización, pero no para la iluminación de una zona.Por su construcción los LED están «polarizados», es decir, no es indiferente conectar un polo u otro de la pila a cada terminal. En caso de equivocarnos el LED no iluminará (VV. AA. Tecnología, 194).

口 s. de acción y efecto. iluminación.

Elsa Quiroz, diseñadora de interiores, da mucha importancia a la iluminación del estudio (El Universal, 25/01/2002).

La franja superior del cristal esmerilado permite la iluminación durante el día y la sensación de la cubierta flotando en el espacio (Trama. Revista de Arquitectura y Diseño, $\left.\mathrm{n}^{\mathrm{o}} 81,03 / 02 / 2003\right)$.

ㅇ adj. agente. iluminador, iluminante.

Luego ingresó en el teatro de La Balaustrada donde trabajó ocho años, como iluminador. Finalmente fue su productor y dramaturgo permanente (El Tiempo, 02/01/1990).

b) En sentido inmaterial, 'aclarar, ilustrar, volver más comprensible una cosa':

En síntesis, creemos que se revela como una acertada antología (no necesariamente se incluirán todos los textos completos) que permite iluminar, con amenidad y carácter no exhaustivo, el panorama teatral de fin de siglo y que incita a la reflexión a teóricos y prácticos del teatro (Stichomythia. Revista de teatro español contemporáneo, $\mathrm{n}^{\mathrm{o}} 0$, 01/2002).

Por lo menos, se puede afirmar que hay una desatención, por parte de los clínicos a aquellos signos que lo evidencian o, en general, a la dimensión explicativa de los fenómenos que considera como clave para iluminar conceptualmente las conductas del ni- 
ño, las relaciones con la madre o los cuidadores primarios antes de los cinco años de vida (Revista de Psicología, XI/ 2, 2002).

En su discurso de ingreso a la Academia Mexicana de Historia y en su libro Memoria mexicana, el historiador citó al novelista estadunidense John Updike. Según éste, la función primitiva del escritor fue servir de banco de la memoria e iluminar cuestiones esenciales para la tribu (Proceso, 27/10/1996).

Camus fue reconocido no por alguna proeza en el estilo o un descubrimiento sorprendente, sino por iluminar con clarividente seriedad los problemas de la conciencia humana de nuestro tiempo (Revista Hoy, 08-14/11/1978 (Chile)).

- Particularmente, 'alumbrar, revelar, hacer claro y manifiesto':

El cuerpo del maestro será enterrado en ultramar, pero su alma iluminará la redención del pueblo judío. Amén (El Mundo, 13/06/1994).

- En construcción pronominal, pasado a suj. el obj. directo:

Piensa que cada vez que sonríes se ilumina una esperanza y se borra una tristeza (Entrena, Animar a desanimados, 135).

口 $s$. de acción y efecto. iluminación.

Esa sensación fue contundente, definitiva, entender algo aunque no entiendas las palabras. Tuve como una especie de iluminación, pequeñilla, de que yo me iba a dedicar a esto, eso fue lo que cerró el círculo (L. Clemente, Kiko veneno, 33).

o adj. agente. iluminador.

Este libro es la reunión (a cargo de Susan Ray, su viuda, autora de un iluminador prólogo sobre su experiencia personal al lado de Ray) de diferentes materiales (La Vanguardia, 01/07/1994).

2. tr. [ alguien (suj.) una cosa <p.e. una calle, una ciudad o monumento> (od.)]. Adornarla o dotarla de algún sistema capaz de emitir luz sobre ella para darle relevancia estética:

El Ministerio de Minas autorizó a las empresas y locales comerciales para iluminar sus establecimientos con adornos navideños, «sin derroche pero con un toque amable y diferente» (El Tiempo, 16/11/1994).

Lo primero que ha hecho el Ayuntamiento desde septiembre ha sido iluminar todos los monumentos romanos de Bernini (El País, 03/01/1981).

Aparte de iluminar la ciudad, el objetivo es resaltar las grandes obras de infraestructura que se hicieron dentro del Plan Vial, especialmente los puentes (El País, 05/11/1997).

o s. de acción y efecto. iluminación.

El Ayuntamiento de Alba de Tormes celebró ayer la adjudicación de las obras de iluminación de las iglesias de Santa Teresa, San Juan y San Juan de la Cruz (El Adelanto, $14 / 11 / 2002)$.

3. tr. [ alguien (suj.) algo (od.) <de un color > (cp.)]. Teñirla con luz de ese color. Se usa probablemente más bien en participio:

Esta maniobra se realiza anteponiendo una lupa de $+10 \mathrm{D}$ a unos $10 \mathrm{~cm}$ del ojo a observar y sobre el eje de luz del oftalmoscopio. Se debe ver la pupila iluminada de rojo (VV. AA., Fundamentos de Oftalmología, 24).

a) Por extensión, 'pintar, colorear':

En 1912, un anticuario norteamericano llamado Wilfrid M. Voynich encontraba un viejo manuscrito en un antiguo convento jesuita llamado Villa Mondragone, en el pueblecito 
italiano de Frascati. Era un volumen de 15 por 27 centímetros, sin cubierta y del que hoy se han perdido unas 28 páginas. El texto, iluminado de azul, amarillo, rojo, castaño y verde, presenta mujeres desnudas, diagramas, plantas imaginarias y una escritura que parece medieval vulgar (Sabadell, El hombre que calumnió a los monos, 183).

b) prnl. Pasando a suj. el obj. directo:

Otro examen en cámara o ambiente oscuro es la trasiluminación que se realiza apoyando sobre la piel de los párpados o sobre la esclerótica, previa anestesia superficial, el extremo luminoso de una linterna. Se observa si la pupila del examinado se ilumina de rosado en forma uniforme (imagen normal) (VV. AA., Fundamentos de oftalmología, 22). Se han formado charcos de lluvia en los pasillos alrededor del patio. Arriba, un pedazo de cielo se ilumina desde un gris acero hasta el suave gris purpurino del pecho de una paloma (E. Santiago, El sueño de América, 41).

口 s. acción y efecto. iluminación.

Dicho reportaje -huele a publicidad- destaca del local el bar y el salón de fumar instalados al final de la sala, detrás de la pantalla, y comenta con grandes elogios la iluminación indirecta de la sala que combina el blanco, el rojo, el verde, al azul, el violeta y el tornasolado con matices que son un placer y descanso de la vista (La Vanguardia, $16 / 03 / 1995)$.

$\otimes$ 4. tr. [ alguien (suj.) un libro o alguna de sus páginas (od.)]. Ilustrarlo, ponerle dibujos o imágenes en general. Se usa sobre todo en participio:

Con el gótico internacional (que se definirá más adelante) la miniatura se hizo, más que nunca, cortesana. En la Francia de la segunda mitad del siglo XIV, Carlos V y sus hermanos Luis de Anjou, Felipe de Borgoña (y sus sucesores en el ducado) y Juan de Berry, además del mariscal Boucicaut, encargaron libros de horas en los que cada página iluminada muestra el mismo detalle, el mismo cuidado y la misma calidad que la pintura sobre tabla contemporánea (Calvo Serraller, Historia del arte, 182).

a) coloq. Se usa irónicamente con el significado de 'escribir notas, signos o comentarios a mano en las páginas de un libro o escrito'. Más usado tal vez en participio: «Tenía el libro de texto todo iluminado».

口 s. acción y efecto. iluminación.

En Inglaterra, corresponde a esta calificación el Apocalipsis de Saint-Albans, un scriptorium monástico, que anuncia la importante escuela cortesana de Westminster; y, ya en el siglo XIV, en los centros de iluminación de manuscritos de la región de East Anglia, se pueden destacar el Salterio de Robert de Lisle o el Salterio de la reina Mary (Clavo Serraller, Historia del arte, 182).

5. a) $t r$. [ alguien o algo (suj.) a otra persona (od.) <en, acerca o sobre algo> (cp.)]. Instruirlo o hacerle ver la verdad o comprender una cosa.

¿Cómo concibe [el hombre de Occidente] el porvenir de los tiempos y podrá iluminar a sus semejantes? Muchas preguntas y corto el paso de ese hombre de Occidente por lo poco visible de su caminar (La información (EE.UU.)).

Para él, la poesía ha sido una revelación y un medio de redención que lo ha iluminado acerca de sus profundidades, que lo ha acompañado en la ardua experiencia de llegar a ser hombre (Proceso, 26/01/1997).

Alfredo Relaño, director de As, Paco González, Santiago Segurola nos han iluminado sobre este esta jornada tan particular, que fue de sueños y pesadillas, como decía muy bien Paco González (Hoy por hoy, 13/03/97, Cadena SER).

- En construcción absoluta: 
Leo HOY porque es bastante objetiva y acoge todos los problemas que afectan al gremio y a los comerciantes que, en este momento, están pasando una difícil situación... Joaquín Luco, médico y Premio Nacional de Ciencias: HOY constituye una esperanza. Si a HOY no le permiten iluminar, la incertidumbre aumentará mañana... (Revista Hoy, 1723/07/1984 (Chile)).

b) prnl. [ - sele a alguien (oi.) la mente, cabeza, entendimiento, el coco, etc. (suj.)]. Tener una inspiración, entender o comenzar a ver con claridad una idea, la solución de un problema o algo semejante:

Edgardo Donato les estaba haciendo escuchar un tango que había compuesto a sus amigos, y mientras estaba sentado al piano en un salón de la ciudad de Montevideo, justo en ese momento se cortó la luz y el local se quedó a oscuras. Pasado ese momento, cuando la luz se reestableció, se le iluminó la mente y le puso nombre a su nuevo tango... lo llamó «A media luz»... (Noticiero De Norte a Sur, $\left.\mathrm{n}^{\circ} 242,10 / 2003\right)$.

A mi padre se le iluminó el coco (C. Fuentes, Cristóbal Nonato, 350).

口 s. acción y efecto. iluminación.

La gran admiración que profesaba a aquellos nombres de nuestras letras que hubieron de emigrar, fue tal vez la iluminación que yo tuve sobre el sentido de nuestra historia (Duque, El suicidio de la modernidad, 119).

Ciertas circunstancias tal vez obliguen a algunos comunicadores sociales a recurrir a la presión para obtener iluminación respecto a hechos que se están investigando (Ruiz Orbegozo, Sugerencias para aprender a exponer en público, pár. 139).

Se divide ésta en dos partes: teórica y práctica y de ambas se hablará en la tercera parte, pero para su distinción, digo que la teórica es la iluminación del intelecto y el conocimiento de la verdad, y que la práctica es la habilidad para el ejercicio de una operación (Muñoz Clavo, Historia de la farmacia en la España moderna y contemporánea, pár. 204).

c) Rel. [ Dios, los santos o la Iglesia (suj.) a alguien (od.) <en algo > (cp)]. Dirigirlo o mostrarle la verdad, el camino o conducta adecuada.

Por la memoria de nuestros muertos en los campos de batalla, trabajemos y consolidemos esta nación que merece un mejor destino y no busquemos en la historia la causa de todos nuestros males, levantemos la cabeza y roguemos a Dios que nos ilumine en nuestras ansias de progreso (Los Tiempos, 15/02/1997).

$\mathrm{Y}$ esto significa en concreto que nos dejemos iluminar por el santo espíritu para que nos indique quienes son los candidatos de buena voluntad (La Prensa de Nicaragua, $02 / 11 / 2004)$.

- El obj. directo puede ser también el alma, entendimiento, conciencia u otro vocablo semejante:

Recordó que la encíclica del Papa Juan XXIII sobre la cuestión social, dice que la Iglesia tiene como misión iluminar a las conciencias en cuanto a su deber de participar en política (Proceso, 27/10/1996).

La Conferencia Episcopal de Nicaragua ha asumido una vez más la responsabilidad de iluminar con la verdad la conciencia y el corazón de los nicaragüenses (La Prensa, 20/05/1997).

- prnl. Pasando a suj. el obj. directo, 'alcanzar el punto culminante de perfección espiritual y exaltación mística':

El séptimo y último chacra, Sahasrara («multiplicado por mil»), se halla situado en la coronilla, en el vértice de la cabeza. Coincide con Pai fui («tres reuniones»), importante punto de acupuntura. Teóricamente, es allí donde se desarrolla la función de conexión con el mundo espiritual. Allí está también el hilo de oro del que pende la vida, allí se produce 
la unión espiritual con la divinidad. En él alcanzan su unidad las energías de la creatividad, el amor, la voluntad; es una síntesis de los atributos divinos en el hombre. En la tradición budista, este es el punto que se ilumina al llegar a la perfección, a la iluminación. Curiosamente, también en la tradición cristiana es aquí donde se ubica el aura (halo) de los santos (Lucena Marotta, Qué significa estar sano, 39).

వ $s$. de acción y efecto. iluminación.

La carrera tenía el otro lado del mundo como meta, un horizonte de oro, plata y piedras preciosas, cuyos dueños no verían inconveniente alguno en ceder a cambio de la iluminación en la Fe Verdadera (El Mundo, 07/06/1994).

Ella dio un quejido, tropezó y cayó de rodillas; seguía mirando la carátula con una expresión de beatería, de iluminación mística (Vargas Llosa, La tçia Julia y el escribidor, 181). Había una vez, en la antigua China, tres monjes budistas que viajaban de pueblo en pueblo dentro de su territorio ayudando a la gente a encontrar su iluminación (Bucay, $\mathrm{El} \mathrm{Ca-}$ mino de la autodependencia, 140).

Buda alcanzó la iluminación bajo el árbol pipal (Iborra Montells, La sanación por los árboles, 28).

6. $t$ r. [ alguien o algo (suj.) el rostro, semblante, ojos, mirada, etc. (od.) a una persona (oi.)]. Hacerle cambiar de expresión a causa de una repentina alegría o entusiasmo. El obj. indirecto puede también expresarse mediante un compl. prep. con de:

No han servido ni las constantes referencias a Trajano (de Sevilla, como González) ni las frecuentes alusiones a los especiales lazos que unen a España con Rumania. Tampoco el singular protocolo que existe en este país o las divertidas situaciones en las que los traductores se empeñaban en interpretar hasta las comas. Nada de esto ha servido para iluminar el cetrino semblante de González (El Mundo, 26/01/1995).

También actuando día como obj. directo:

Elaborar manualidades puede resultar entretenido. ¿Por qué no iluminar el día de alguien con un regalo hecho con tus manos? (La Prensa de Nicaragua, 31/12/2001).

a) prnl. Pasando a suj. el obj. directo, 'mostrar alegría o entusiasmo':

La operación en el hospital de Caridad fue rápida y con buen pronóstico. Cuando le quitaron las vendas, sentada en la cama, abrió los ojos radiantes de su nueva juventud, se le iluminó el rostro y resumió su alegría con una sola palabra: - Veo (García Márquez, Vivir para contarla, 207).

Cuando Perla, su nieta, le depositó en las piernas una computadora portátil y un telégrafo, a don Júbilo se le iluminó la cara (L. Esquivel, Tan veloz como el deseo, 112).

Viste ropa oscura, no eclesiástica, $y$, lentes. Su mirada se ilumina al ver al padre que entra presuroso (Santander, Y, el milagro, pár. 120).

- Con un compl. con de para indicar la alegría o el entusiasmo:

Al verme despierto, «en estado satisfactorio», su rostro cenizoso se le iluminó de puro contento, enderezó los hombros y dio unos pasos cortos (E. Quintero, La danza del jaguar, 233).

En efecto, quiere saber por Werner a quién pertenece una de esas dos fisonomías infames. Leni se refiere a los dos jefes de la organización letal, y Werner se ilumina de ansiedad, puesto que piensa que Leni ha reconocido en uno de ellos al criminal que él mismo condenara a muerte, para consternación de su amada (M. Puig, El beso de la mujer araña, pár. 99).

b) prnl. Actuando como suj. la persona afectada, 'cambiar de expresión a causa de la alegría, entusiasmo, etc.':

Pero Mar se ilumina, cambia y hasta se infantiliza, cuando ríe. Ahí vence porque convence. Sonreír es su arma más poderosa con ella ilumina su mirada y ya no hay quien se 
le resista incluso luciendo un traje como este remarcador de un trasero casi tan imperfecto como su presente (Época, 06/04/1998).

Aunque la lectura de estos dos ejemplos haya resultado un tanto tediosa para el lector, espero que bien habrá merecido la pena al poder así comprobar la eficacia del procedimiento lexicográfico propuesto, procedimiento que, como habrá podido observarse, en el Diccionario «Coruña», no se reduce al caso de los sustantivos deverbales de acción, efecto, etc., sino también a otros derivados nominales, como los adjetivos en -ble, -dor (-tor y -sor), etc., de los que aquí, obviamente, no era mi objetivo ocuparme.

\section{REFERENCIAS BIBLIOGRÁFICAS}

COSERIU, E. (1977): Principios de semántica estructural, Gredos, Madrid.

$D E A=$ Diccionario del español actual. Véase Seco y otros.

$D R A E=$ Diccionario de la lengua española. Véase Real Academia Española (2014).

$D U E=$ Diccionario de uso del español. Véase Moliner.

DUEAE = Diccionario de uso del español de América y España. Véase VOX.

GARCÍA GARCÍA-SERRANO, M. Á. (2004): «Los nombres de acción en algunos diccionarios del español», Revista de Lexicografía, X, pp. 81-101.

LÁZARO CARRETER, F. (1971): «Transformaciones nominales y diccionario», Revista Española de Lingüística, 1, 2, pp. 371-379.

MARTín GARCÍA, J. (2011): «Sobre la acción y el efecto del verbo», Revista de Lexicografía, XVII, pp. 97-114.

Moliner, M. (1966-1967): Diccionario de uso del español, Gredos, Madrid (2a ed. 1998, $3^{\mathrm{a}}$ ed. 2007).

PORTO DAPENA, J.Á. (2006): «La definición lexicográfica de tipo relacional», Boletín de la Real Academia Española, LXXXVI, pp. 333-362.

Porto DAPENA, J.-Á. (2009): Lexicografia y metalexicografía. Estudios, propuestas y comentarios, A Coruña, Universidade da Coruña, pp. 51-72.

Porto DapenA, J.-Á. (2014): La definición lexicográfica, Madrid, Arco/Libros.

RAFEL I FONTANALS, J. (2005): Lexicografía, Barcelona, UOC.

REAL ACADEMia EsPaÑola (2009): Nueva gramática de la lengua española, Madrid, Espasa-Calpe.

Real ACADEmia Española (2014): Diccionario de la lengua española, $23^{\mathrm{a}}$ ed., Madrid, Espasa.

RIBERA, J. (1918): «Los nombres de acción en el Diccionario actual de la Academia», Boletín de la Real Academia Española, V, pp. 281-297.

Seco, M., O. De Andrés y G. RAmos (1999): Diccionario del español actual, Madrid, Aguilar.

VOX (2002): Diccionario de uso del español de América y España, Barcelona, Spes. 